\title{
Ellectron Beam Optics for the FEL Experiment and IFEL Experiment*
}

\author{
A. van Steenbergen \\ BNL --46840 \\ DE92 005049
}

National Synchrotron Light Source

Resume: Electron beam transport system parameters for the FEL experiment and for the IFEL experiment are given. The perturbation of the "interaction region" optics due to wiggler focussing is taken into account and a range of solutions are provided for relevant Twiss parameters in the FEL or IFEL region. Modifications of the transport optics in specific sections of the overall beam transport lines, for reasons of enhanced diagnostic capability or enhanced beam momentum analysis resolution, is also presented.

Introduction: Three beam lines will be available, in time, from the ATF linear accelerator (see Fig. 1). The first one, designed for a low intensity beam only, will have as its principal focus laser acceleration of electrons by means of micro linac structures and related experiments (Beam Line I). The second beam line will permit the exploration of shorter wavelength FEL's (Beam Line II), and the third one is planned for a variety of experiments including the testing of an Inverse Free Electron Laser (IFEL) accelerator demonstration module (Beam Line III). In the following the electron beam optics of Beam Line II (Part B of the report) and Beam Line III (Part $\mathrm{C}$ of the report), will be dealt with. Before doing so, a short lead-in section (Part A of the report) is given, dealing with the perturbation of the FEL or IFEL interaction region optics due to wiggler electron beam focussing.

*This work was performed under the auspices of the U.S. Department of Energy.

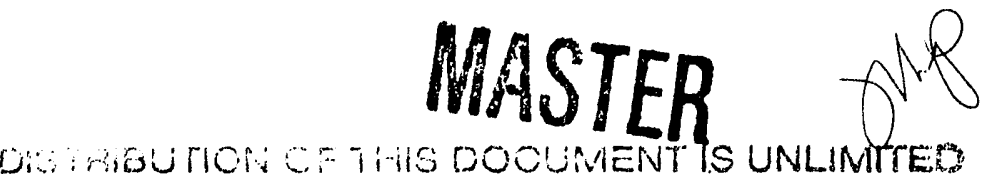




\section{Part A. Wiggler Optics}

As is well known, the wiggler field distribution introduces a transverse focussing effect in the plane perpendicular to the electron orbit wiggle. In a first approximation there is no net focussing effect in the plane of the wiggling orbit, provided the "first" field integral $\int B_{y} d z=0$ and there is symmetry about the "midpoint" of the wiggler. The relevant geometry is show in Fig. 2. The y oriented focussing effect is due to the Lorentz force $v_{x}{ }^{*} B_{z}$ for off axis electrons, with a consequent deflection which is always directed towards the axis. By averaging the focussing component over each period of the wiggler, it is possible to write the transfer matrix for the whole wiggler in the form of ${ }^{1}$ :

$$
\begin{gathered}
M_{v}=\left|\begin{array}{cc}
\cos \theta & \beta_{w} \sin \theta \\
-\frac{\sin \theta}{\beta_{w}} & \cos \theta
\end{array}\right| \text { with } \theta=\sqrt{K_{y}} L \text {, and } \beta_{w}=\frac{1}{\sqrt{K_{y}}}=\frac{L}{\theta} \\
K_{y}\left(=\text { "focussing strength") }=\frac{1}{2 \rho_{o}^{2}}\right. \text { with } \\
\rho_{o}=\left(\frac{m c \gamma}{e B_{o}}\right)=\frac{\lambda_{o} \gamma}{2 \pi K}=\frac{3.33 E}{B_{0}} \quad[m . G e V . T]
\end{gathered}
$$

The $M_{v}$ matrix is identical to that of a quadrupole magnet focussing in the vertical plane. The associated period of the betatron oscillation introduced follows as:

$$
\begin{gathered}
\lambda_{\beta}=\frac{2 \pi}{\sqrt{K_{y}}}=2 \sqrt{2} \pi \rho_{o}, \text { with an equivalent local } \beta \text { function amplitude of } \\
\beta_{w}=\left(\frac{\lambda_{\beta}}{2 \pi}\right)=\sqrt{2} \rho_{0}
\end{gathered}
$$


a) Wiggler Optics, finite width poles

For a wiggler the appropriate field expansion is given by Halbach as:

$B_{x}=\left(k_{x} / k_{y}\right) \cdot B_{0} \cdot \sinh \left(k_{x} x\right) \cdot \sinh \left(k_{y} y\right) \cdot \cos k z$

$B_{y}=\quad B_{0} \cdot \cosh \left(k_{x} x\right) \cdot \cosh \left(k_{y} y\right) \cdot \cos k z$

$B_{z}=-\left(k / k_{y}\right) \cdot B_{o} \cosh \left(k_{x} x\right) \cdot \sinh \left(k_{y} y\right) \cdot \sin k z \quad$ with,

$\mathrm{k}=\left(2 \pi / \lambda_{\mathrm{o}}\right)$ and $\mathrm{k}_{\mathrm{x}}{ }^{2}+\mathrm{k}_{\mathrm{y}}{ }^{2}=\mathrm{k}^{2} ; \quad \lambda_{\mathrm{o}}=$ wiggler period length

Close to the wiggler axis the $B_{y}(x)$ component and the $B_{y}(y)$ component are approximated by:

$\mathrm{B}_{\mathrm{y}}(\mathrm{x})=\mathrm{B}_{\mathrm{yo}} \cdot \cos (\mathrm{kz}) \cdot\left[1+\left(\mathrm{k}_{\mathrm{x}} \mathrm{x}\right)^{2 / 2}\right]$ and

$B_{y}(y)=B_{y o} \cdot \cos (k z) \cdot\left[1+\left(k_{y} y\right)^{2} / 2\right]$

$\mathrm{k}_{\mathrm{x}}=0$ for infinite wide poles. For finite widh poles $\mathrm{k}_{\mathrm{x}}$ is non zero and imaginary.

The (de)focussing strengths, to first order, for the case $k_{x} \neq 0$, are given by ${ }^{2}$ :

$$
K_{x}=\frac{r^{2}}{2 \rho_{o}^{2}\left(1+r^{2}\right)} ; K_{y}=\frac{1}{2 \rho_{o}^{2}\left(1+r^{2}\right)} \text { with } r^{2}=\left(\frac{k_{x}{ }^{2}}{k_{y}}\right.
$$

[Note: $k_{x}=0(r=0)$ yields $K_{x}=0 ; K_{y}=\frac{1}{2 \rho_{o}^{2}}$, as above]

To obtain now approximate values $\mathrm{K}_{\mathrm{x}}, \mathrm{K}_{\mathrm{y}}$, it is assumed that the transverse field fall-off is as described by Halbach's equations, i.e. $\underline{\alpha} \cosh \left(\mathrm{k}_{\mathrm{y}}, \mathrm{x}\right)$ and further that, arbitrarily, $B_{y}(x= \pm d / 2)=\left(B_{y o} / 2\right) \cos (k z)$. It then follows readily: 


$$
\begin{gathered}
k_{x}=\left(\frac{2}{d}\right) i ; \text { and with } k^{2}=\left(2 \pi / \lambda_{\partial}\right)^{2}=k_{x}^{2}+k_{y}^{2}, \\
k_{y}=\left[\left(2 \pi / \lambda_{\partial}\right)^{2}-k_{x}^{2}\right]^{1 / 2} \text { or, } \\
r_{2}=-\left[\frac{(2 / d)^{2}}{\left(2 \pi / \lambda_{\partial}\right)^{2}+(2 / d)^{2}}\right] \text {, and with this the magnitudes of } K_{x}, K_{y}
\end{gathered}
$$

\section{Wiggler Optics, numerical values}

Using the FEL wiggler specifications and the foregoing equations:

$$
\begin{gathered}
B_{o}=0.47[T] ; E=0.05[\mathrm{GeV}] \rightarrow \rho_{o}=0.354[\mathrm{~m}] \\
\lambda_{\beta}=2 \sqrt{2} \pi \rho_{o}=3.136[\mathrm{~m}] ; k_{\beta}=\frac{2 \pi}{\lambda_{\beta}}=\frac{1}{\sqrt{2} \rho_{o}}=2.0\left[\mathrm{~m}^{-1}\right] \\
\beta_{w}=\left(\frac{\lambda_{\beta}}{2 \pi}\right)=\sqrt{2} \rho_{o}=0.499[\mathrm{~m}] \equiv \beta_{w}\left(" \text { nat }{ }^{\prime \prime}\right)
\end{gathered}
$$

Wiggler infinite wide poles:

$$
k_{x}=0 ; k_{y} \neq 0, r^{2}=0: \quad K_{x}=0 ; K_{y}=\frac{1}{2 \rho_{o}^{2}}=3.99\left[m^{-2}\right]
$$

Wiggler finite width poles: 
Wiggler $g=4.4[\mathrm{~mm}] ; \lambda_{o}=8.8[\mathrm{~mm}] ; d=12[\mathrm{~mm}], L=0.6[\mathrm{~m}]$

$$
\begin{gathered}
k_{x}=0.166 i\left[\mathrm{~mm}^{-1}\right] ; k=0.714\left[\mathrm{~mm}^{-1}\right] \\
k_{y}=0.733\left[\mathrm{~mm}^{-1}\right] ; \text { hence } r^{2}=-0.05, \text { or } \\
K_{x} \approx-0.05\left(\frac{1}{2 \rho_{o}^{2}}\right) ; K_{y}=\left(\frac{1}{2 \rho_{o}^{2}}\right)
\end{gathered}
$$

Clearly, for reasonable assumptions of transverse field fall-off, the $\mathrm{K}_{\mathrm{x}}$ (de)focussing component is negligible relative to the $\mathrm{K}_{\mathrm{y}}$ component, hence, in the system transport computations only the $\mathrm{K}_{\mathrm{y}}$ focussing component has been taken into account.

Transport Optics, as modified by Wiggler Focussing

The effect on the overall optics, resulting from the transfer matrix of the wiggler in the y plane, can be obtained by introducing it into a standard transport program. Alternatively, analytically, this can also be done by rewriting the matrix as a point like perturbation matrix given by':

$$
M_{V}^{*}=\left|\begin{array}{cc}
\cos \theta^{*} & \beta^{*} \sin \theta^{*} \\
-\sin \frac{\theta^{*}}{\beta^{*}} & \cos \theta^{*}
\end{array}\right|
$$

with $\cos \theta^{*}=\cos \theta+\frac{\theta}{2} \sin \theta$ and $\beta^{*}=L\left(\frac{1}{\theta^{2}}-\frac{\operatorname{cotg} \theta}{\theta}-\frac{1}{4}\right)^{1 / 2}$

Using the foregoing, and substituting numerical values: 


$$
\theta=1.2 ; \beta_{w}=0.499[\mathrm{~m}]: \theta^{*}=0.4, \beta^{*}=0.21[\mathrm{~m}]
$$

Using now either the approach of inserting a finite length wiggler with beta function parameters $\left(\beta_{y}, \alpha_{y}\right)$ at the entrance to the wiggler given by $\beta_{y}=\beta_{w} ; \alpha_{y}=0$; or, alternatively, inserting a zero length wiggler with point perturbation matrix $M_{v}$ at the midpoint of the wiggler and matching to the local beta function values $\beta_{\mathrm{y}}=\beta^{*}, \alpha_{\mathrm{y}}=0$, should yield equivalent results in the transport optical computations.

In actual FEL transport line computations, only the first approach has been used since the available transport program (BETA) permits a more realistic insertion of the wiggler ("10 slices/period, full length wiggler insertion).

Local Optics, optimized for FEL interaction

Electrons deviating in position and/or angle from the axial electrons will experience smaller $\beta_{z}$ components compared with the on-axis electrons. This will affect the resonance condition and, hence, the FEL gain. As expressed by Walker ${ }^{3}$ the $\Delta \beta_{z}$ deviation, for electrons with non zero $y, y^{\prime}$ values, is given by:

$$
\Delta \beta_{z}=-\frac{K^{2}}{2 \gamma^{2}} \frac{\left(k_{y} y\right)^{2}}{2}-\frac{y^{\prime 2}}{2}
$$

with $K_{y}=\frac{1}{2 \rho_{0}^{2}}$ and $\rho_{0}=\frac{\lambda_{0} \gamma}{2 \pi K}$, this can readily be written as:

$$
-\Delta \beta_{z}=K_{y} y^{2}+y^{\prime 2}
$$


It can be shown that the RHS of this expression is an invariant in transport through the wiggler. It, in effect, provides for the vertical phase space orientation and eccentricity parameters for minimum effect on $\Delta \beta_{z}$. Quantitatively, it follows, for this case, that the local matching requires an upright ellipse $\left(\alpha_{\mathrm{y}}=0\right)$ with beta function magnitude given by:

$$
\begin{aligned}
& {\left[\frac{y(\max )}{y^{\prime}(\max )}\right]=\frac{1}{\sqrt{K_{y}}}=\beta_{y} ; \text { equal in effect to the }} \\
& \text { "natural" } \beta \text { function magnitude given above as } \beta_{w}=\left(\frac{1}{\sqrt{K_{y}}}\right)
\end{aligned}
$$

Specifically also, matching the vertical phase space to the entrance of the wiggler, with $\beta_{y}=\beta_{w}, \alpha_{y}=0$, will result in such phase space transport through the wiggler that both its orientation and eccentricity will not vary, i.e., vertically, for $\left[\beta_{y}=\beta_{w}, \alpha_{y}=0\right]_{i}$ the transport through the wiggler behaves like a drift space of zero length.

For the FEL optics computations, the approach has been now to compute the overall optical system first without wiggler, but demanding local (where the center of the wiggler would be placed) beta function parameters given by, eg., $\beta_{\mathrm{x}}{ }^{*}=\beta_{\mathrm{y}}{ }^{*}=0.2[\mathrm{~m}], \alpha_{\mathrm{x}}=\alpha_{\mathrm{y}}=\eta=\eta^{\prime}=0$; then, subsequently, to insert the wiggler and recomputing the overall set of transport system parameters, in this case covering the parameter range $0.1 \leq \beta_{\mathrm{x}}{ }^{*}=\beta_{\mathrm{y}}{ }^{*}<0.9[\mathrm{~m}], \alpha_{\mathrm{x}}{ }^{*}=\alpha_{\mathrm{y}}{ }^{*}$ $=\eta^{*}=\eta^{\prime *}=0$.

A comparison of relevant parameters indicating the effect of the wiggler focussing perturbation, for the case of the FEL and IFEL, resp., is given in Table I. 


\section{Part B, Electron Beam Optics, Beam Line II, FEL Experiment}

The electron beam transport to the three ATF experimental interaction regions makes use of a short, common, transport line, downstream of the ATF linac, with the possibility of transverse emittance magnitude control by means of two collimators. ${ }^{4,5}$ The optics of this section, defined here specifically as the section between the exit of the linac and the center of the second collimator, encompasses six quadrupole magnets providing adequate flexibility of "shaping" the $x, y$ transverse emittances at the location of the second collimator (using only four of the six quadrupoles and linac exit parameters, $\beta_{x, y}=10 \mathrm{~m}, \alpha_{\mathrm{x}}=\alpha_{\mathrm{y}}=\eta=\eta^{\prime}=0$, it was readily possible to vary the beta function amplitudes at the location of the second collimator in the range of $0.1 \leq \beta_{x, y} \leq 10[\mathrm{~m}]$, with $\alpha_{x}=\alpha_{y}=0$.) Therefore, in what follows, consistently, the input location $(s=0)$ of Beam Line II (and of Beam Line III, resp.), is taken to be the center of the second collimator of the common optics line downstream of the linac, with assumed Twiss parameters $\beta_{x, y}(s=0)=10[\mathrm{~m}], \alpha_{x}=\alpha_{y}=\eta=\eta '=0$ at $s=0$. It is similarly assumed that, in case the linac exit Twiss parameters are different from what is presently assumed, the manipulation of the common line optics six quadrupole set can readily restore the Twiss parameter set as assumed here at the location of the second collimator. It is noted in this respect that the measurement of the linac exit beam emittance orientation and eccentricity is a necessary ingredient in unambiguously defining the correct Beam Line II optics.

At the FEL interaction region a dispersion free beam is desired. Because of the relative location of the dipoles and mirrors for the FEL optical cavity, at least six free quadrupole parameters are required to obtain the desired beam parameters at the center of the FEL cavity interaction region. Typical local Twiss parameters, neglecting in a first approach the vertical 
focussing contribution of the wiggler, are $\beta_{\mathrm{x}}{ }^{*}=\beta_{\mathrm{y}}{ }^{*}=0.2[\mathrm{~m}], \alpha_{\mathrm{x}}=\alpha_{\mathrm{y}}=\eta=\eta^{\prime}=0$, leading, with an emittence of $710^{8} \mathrm{~m}$.rad, to local beam $\sigma$ values give by $\sigma_{\mathrm{x}}=\sigma_{\mathrm{y}}=0.125 \mathrm{~mm}$. The basic set of FEL beam transport elements, locations and parameters for this case is given in Table II. Extensive optical matching trials showed that with seven selected (see "starred" designation in Table II) quadrupoles (the transport system incorporates 10 quadrupoles between "source location" and wiggler interaction region) beta function variation in the range of $0.1 \leq \beta_{x, y}^{*} \leq$ 1.[m] with $\alpha_{\mathrm{x}}=\alpha_{\mathrm{y}}=\eta=\eta$ ' $=0$, at the interaction "point" could readily be achieved, for optimum overlap adjustment of laser-electron beams. The beam amplitude ( $\mathrm{x}$ and $\mathrm{y}$ ) for the case of $\beta^{*}{ }_{x}=\beta^{*}{ }_{y}=0.5[\mathrm{~m}], \alpha_{x}{ }^{*}=\alpha_{y}{ }^{*}=\eta^{*}=\eta^{*}=0$, with $\epsilon_{x}=\epsilon_{y}=710^{-8} \mathrm{~m} \cdot \operatorname{rad}$ and $\delta(\Delta p / p)=0.0$ or 0.3 , is given in Fig. 3. A summary of a set of optical solutions is given in Table III for the case without wiggler perturbation. Taking the wiggler perturbation into account, no modification of the optics was required for the case $\beta_{\mathrm{x}, \mathrm{y}}^{*}=0.2[\mathrm{~m}]$, whereas only minor corrections in the optics were required for the cases $\beta_{x, y}^{*}=0.5[\mathrm{~m}]$, and $\beta_{y, y}^{*}=0.8[\mathrm{~m}]$. The relevant parameters for these cases are also tabulated in Table III. The commensurate beta function behavior in the FEL interaction region is illustrated in Figs. 4,5 and 6 for the cases: $\beta_{x, y}^{*}=0.2[\mathrm{~m}], \beta_{x, y}^{*}=0.5[\mathrm{~m}]$ and $\beta_{\mathrm{x}, \mathrm{y}}^{*}=0.8[\mathrm{~m}]$, respectively. Note that for the FEL wiggler, with $\rho_{\mathrm{o}}=0.354[\mathrm{~m}]$, the $\beta_{\mathrm{w}}$ $($ "nat") $=0.5[\mathrm{~m}]$.

\section{Isochronous Condition}

As is evident above, the optical matching was carried out requiring achromaticity from the common downstream section of the linac to the FEL interaction region, but not necessarily isochronicity. For the "final" optical solutions, the path length difference for "on and off" momentum electrons was checked with the following results for a typical case $\left(\beta^{*}=0.5 \mathrm{~m}\right)$ : 
Isochronicity requires (in case of $\epsilon=0$ ) that the transport matrix elements $R_{51}=R_{52}=$ $R_{56}=0$. The path length difference $\Delta \ell$ is given by $\Delta \ell=R_{51} x_{0}+R_{52} x_{0}^{\prime}+R_{56} \delta$, where $\delta=(\Delta \mathrm{p} / \mathrm{p})$. For the relevant case $\mathrm{R}_{51}=\mathrm{R}_{52}=0, \mathrm{R}_{56}=1.43510^{-2}$ for the total transport section $s=0$ to $s=*$ interaction region. Hence, $\Delta \ell$ equals $\pm\left(310^{-3}\right)\left(1.43510^{-2}\right)= \pm 4.3$ $10^{-5}[\mathrm{~m}] ;$ or $\Delta \mathrm{t}= \pm \ell / \mathrm{c}= \pm 0.14 \mathrm{psec}$ for the $\delta$ value, as stated. The ATF microstructure pulse width equals 6 psec., hence the incurred time dispersion is nearly negligible.

In order to check ease of further correctibility of this non-isochronicity of the relevant transport section, a minor refinement in the optical matching was imposed, resulting in a $\mathbf{R}_{56}$ magnitude of $R_{56}=2.510^{-3}$, hence a time dispersion of $\Delta t= \pm 0.025 \mathrm{psec}$ for $\delta= \pm 310^{-3}$. Electron Beam Transport Aspects for Enhanced Diagnostics

Substantial attention has been devoted to the capability of electron beam diagnostic analysis. ${ }^{6}$ To this end the FEL and IFEL beam line designs include arrays of high-precision electron beam diagnostic tools. These include stripline monitors, "fast" beam profile monitors for the measurement of the time dependent electron beam energy profile and high precision screens with CCD cameras. For optimized electron beam analysis, two sections of the overall FEL beam transport system have been examined further in order to potentially enhance the electron beam momentum analysis. The first section concerns the transport section immediately downstream of the second collimator, bridging the first $20^{\circ}$ dipole magnet in the transport line. With the intent of enhanced momentum resolution during the commissioning trials of the linac, special optical solutions have been arrived at which enhance the ratio $\left(\eta \delta / \sigma_{\mathrm{x}}\right)$ (note: $\eta=$ local dispersion value, $\left.\delta=(\Delta \mathrm{p} / \mathrm{p}), \sigma_{\mathrm{x}}=\sqrt{\beta_{\mathrm{x}} \epsilon_{\mathrm{x}}}\right)$ at the location of the CCD beam profile monitor. This is further illustrated in Fig. 7 where $\left(\eta \delta / \sigma_{x}\right)$ ratio values in the ranges of 
$8 \leq\left(\eta \delta / \sigma_{\mathrm{x}}\right) \leq 15$ were obtained. This ratio, for the standard FEL transport case, at the (CCD) location of the first quadrupole downstream of the $20^{\circ}$ bend magnet is, typically, $\left(\eta \delta / \sigma_{x}\right) \simeq 2$.

The fast beam profile monitor makes use of a time synchronized vertical deflection unit located immediately downstream of the second collimator. This is further illustrated in Fig 8 where the beam dispersion and effect of a vertical kick of $\theta_{\mathrm{v}}=1 \mathrm{~m}$ rad is given at the locations of the profile monitoring CCD's, for the "standard", $\beta^{*}=0.5$ [m], FEL optics.

The second beam transport section of special diagnostic relevance is the section immediately downstream of the FEL interaction region. In this case both the possibility of high momentum resolution at the beam dump profile monitoring location and reduced momentum resolution mod, (because of $\mathrm{CCD}$ element transverse dimension restrictions) have been addressed. This is illustrated in Fig. 9 where resolution magnitudes in the range of $(10 \mathrm{~mm} / 1 \%(\Delta \mathrm{p} / \mathrm{p})>\mathrm{R}>2.5 \mathrm{~mm} 1 \%(\Delta \mathrm{p} / \mathrm{p})$ are indicated together with commensurate values of vertical fast deflection effects of $1.7 \mathrm{~mm} / 1 \mathrm{mrad} \theta_{\mathrm{v}}<\Delta_{\mathrm{v}}<3.0 \mathrm{~mm} / 1 \mathrm{mrad} \theta_{\mathrm{v}}$.

For completeness sake, and in order to further assist the optimum location of diagnostic elements, the dispersion magnitude in the overall FEL transport system for the standard FEL optics solution $\left(\beta^{*}=0.5[\mathrm{~m}]\right)$ is given in Fig. 10 . 


\section{Part C, Electron Beam Optics, Beam Line III, IFEL Experiment}

For the IFEL beam transport optics, the manner by which the photon beam and electron beam are brought into coincidence within the wiggler is different from that what must be employed in the FEL optical arrangement. This is evident from Fig. 1 and is further indicated, for the IFEL case, schematically in Fig. 11. Hence, the achromatic translation from the second collimator location to the downstream part of the second $20^{\circ}$ bend section is straight forward, providing for the possibility of adopting only four "variable" matching quadrupoles in the dispersion free downstream section segment. Downstream of this, a minimum displacement ( $\sim$ $2 \mathrm{~cm}$ ) bypass section will permit the axial location of the mirror in the laser beam coupling section without introducing dispersion in the IFEL interaction region proper.

As indicated in Table I, the perturbation due to the vertical focussing of the wiggler in the IFEL case is significantly greater than for the FEL case, and hence, must be taken into account in the transport optical solutions. This has been done analogously as indicated in the foregoing for the FEL case. The IFEL wiggler "natural" beta amplitude is given by $\beta_{w}($ "nat" $) \simeq 0.2 \mathrm{~m}$. The IFEL transport elements, location and parameters for a typical matched case with $\beta_{\mathrm{x}, \mathrm{y}}{ }^{*}=0.3 \mathrm{~m}$ is given in Table IV and the commensurate beam sizes and dispersion magnitude for the overall IFEL optical transport system is given in Fig. 12.

Note: The final crystallization of the FEL and IFEL electron beam transport benefitted from discussions with J. Gallardo, H. Kirk, J. Rogers, X.J. Wang and M. Woodle. 


\title{
References
}

1. M. Bassetti et al., INFN Frascati Report LNF 77,26,1977.

2. L. Farvacque et al., ESRF-SR/LAT-88.08.

3. R. Walker, NIM 214, p. 497, 1983.

4. H.G. Kirk, CAP-ATF Tech. Note

5. X.J. Wang, H. G. Kirk, BNL Rep. 43307.

6. J. Rogers, private communications.

\section{DISCLAIMER}

\begin{abstract}
This report was prepared as an account of work sponsored by an agency of the United States Government. Neither the United States Government nor any agency thereof, nor any of their employees, makes any warranty, express or implied, or assumes any legal liability or responsibility for the accuracy, completeness, or usefulness of any information, apparatus, product, or process disclosed, or represents that its use would not infringe privately owned rights. Reference herein to any specific commercial product, process, or service by trade name, trademark, manufacturer, or otherwise does not necessarily constitute or imply its endorsement, recommendation, or favoring by the United States Government or any agency thereof. The views and opinions of authors expressed herein do not necessarily state or reflect those of the United States Government or any agency thereof.
\end{abstract}

Note: This report replaces prior issued handwritten notes "Update FEL Optics, March 1990" and "Up-Update FEL Optics, November 1990". 


\section{Table I}

Comparison Insertion Effect, FEL Wiggler and IFEL Wiggler

\begin{tabular}{||l|l|l||}
\hline & FEL & IFEL \\
\hline $\mathrm{E}(\mathrm{GeV})$ & 0.05 & 0.05 \\
\hline $\mathrm{B} \rho(\mathrm{Tm})$ & 0.16675 & 0.16675 \\
\hline $\mathrm{B}(\mathrm{max})$, Wiggler(T) & 0.47 & 1.25 \\
\hline$\rho_{\mathrm{o}}(\mathrm{m})$ & 0.354 & 0.133 \\
\hline $\mathrm{Ky}\left(\mathrm{m}^{-2}\right)$ & 4.0 & 28.27 \\
\hline $\int \mathrm{K}_{\mathrm{y}} \mathrm{ds}\left(\mathrm{m}^{-1}\right)$ & 2.4 & $16.96^{*}$ \\
\hline$\theta$ & 1.2 & 3.10 \\
\hline $\mathrm{L}(\mathrm{m})$ & 0.6 & 0.6 \\
\hline$\beta_{\mathrm{w}}\left({ }^{\prime \prime}\right.$ nat") (m) & 0.5 & 0.19 \\
\hline
\end{tabular}

*Transport line quadrupole components, typically $\leqslant 1\left(\mathrm{~m}^{-1}\right)$ 
Table II

FEL Beam Transport Elements, Location and Parameters* $\left(\rho_{\mathrm{o}}=50 \mathrm{MeV} / \mathrm{c}\right)$

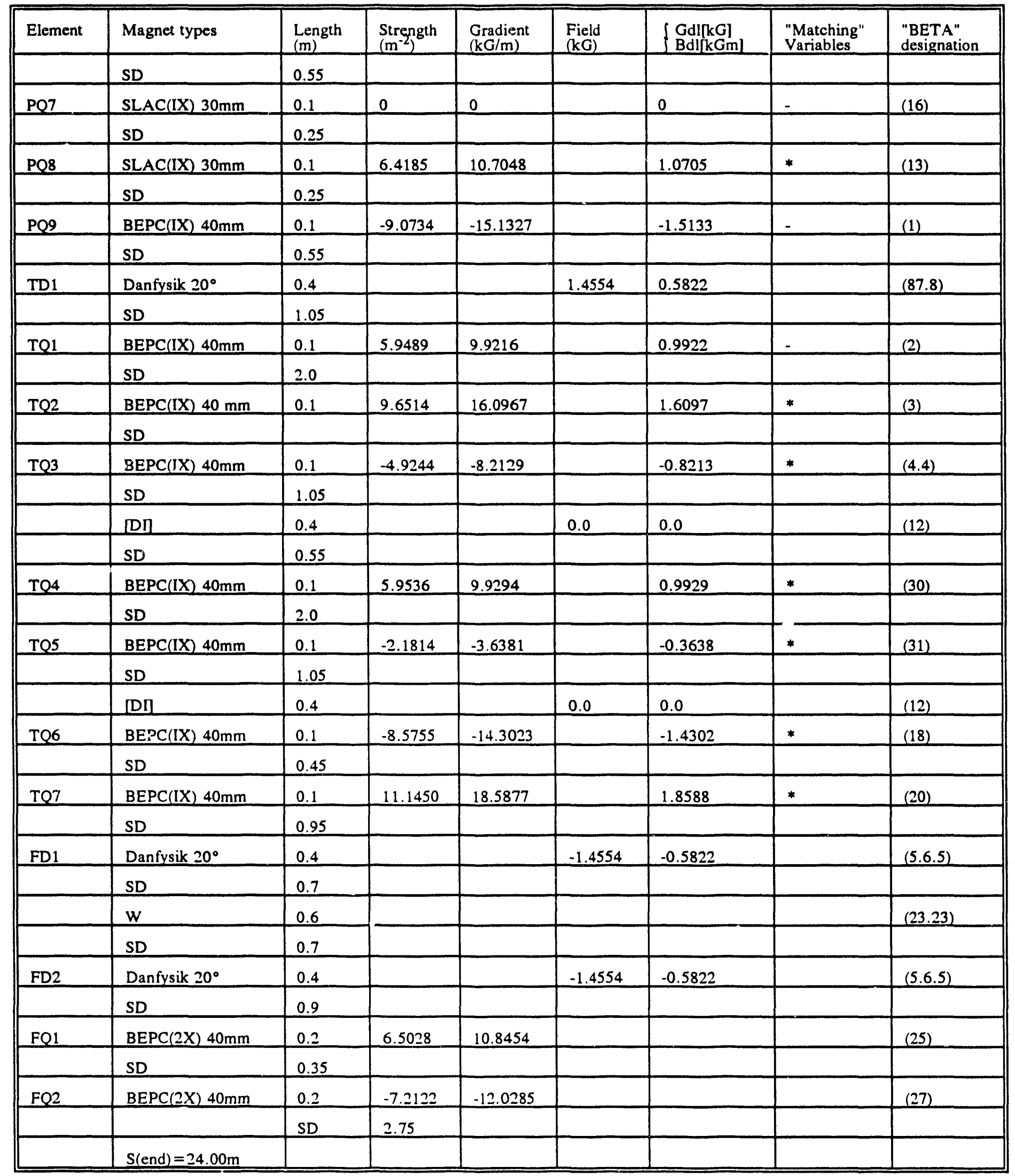

*Optical parameters: at Collimator II; $\beta_{\mathrm{x}}-\beta_{\mathrm{y}}=10.0[\mathrm{~m}], \alpha_{\mathrm{x}}=\alpha_{\mathrm{y}}=\eta=\eta^{\prime}=0=0$.

at Interaction "point"; $\beta_{x}{ }^{*}=\beta_{y}{ }^{*}=0.2[\mathrm{~m}], \alpha_{x}^{*}=\alpha_{y}^{*}=\eta^{*}=\eta^{*}=0.0$ 


\section{Table III}

Transport Quadrupole Parameters for Various Matched Conditions in the FEL Interaction Region (All cases: $\beta_{\mathrm{x}}^{*}=\beta_{\mathrm{y}}{ }^{*}=\beta^{*}[\mathrm{~m}] ; \alpha_{\mathrm{x}}{ }^{*}=\alpha_{\mathrm{y}}{ }^{*}=\eta^{*}=\eta^{*}=0$

\begin{tabular}{||l|l|l|l|l|l||}
\hline Quad.**** & $\beta^{*}=0.1$ & $\beta^{*}=0.2$ & $\beta^{*}=0.5 * * * *$ & $\beta^{*}=0.8$ & $\beta^{*}=0.9$ \\
\hline 3 & 7.9480 & 0.6002 & $9.3389 * *$ & 9.7714 & 9.3208 \\
\hline 4 & -4.8579 & -4.9176 & -5.9405 & -6.0989 & -6.1273 \\
\hline 30 & 6.0941 & 5.9455 & 5.1924 & 4.8271 & 4.8427 \\
\hline 31 & -2.2871 & -2.1674 & 0.1174 & 0.8734 & 0.9054 \\
\hline 18 & -8.5781 & -8.5926 & -7.8808 & -6.6359 & -5.3361 \\
\hline 20 & 11.4297 & 11.1579 & 9.2426 & 7.2801 & 5.8302 \\
\hline 13 & 5.4144 & 6.4185 & 8.5493 & 8.7973 & 9.3317 \\
\hline 3 & & $* * * * *$ & 9.0503 & $n$ & \\
\hline 4 & & $*$ & -5.9222 & $*$ & \\
\hline 30 & & $*$ & 5.0899 & $*$ & \\
\hline 31 & & $*$ & 0.3717 & $*$ & \\
\hline 18 & & $*$ & -8.3355 & -7.0500 & \\
\hline 20 & & $*$ & 9.7898 & $*$ & \\
\hline 13 & & $* * * * *$ & 8.3995 & $*$ & \\
\hline
\end{tabular}

**This quadrupole parameter set is designated " $\mathrm{Q}_{\text {set }}\left(\beta^{*}=0.5,-\mathrm{W}\right)$ ". The other quadrupole parameter sets are indicated analogously.

***Only "variable" quadrupoles are given here. For complementary transport parameters, see Table II.

$* * * *$ For the FEL wiggler case, $\beta_{w}("$ nat") $=0.5 \mathrm{~m}$ (see text).

${ }^{* * * * *} \mathrm{Q}_{\text {set }}\left(\beta^{*}=0.2,+\mathrm{W}\right) \approx \mathrm{Q}_{\text {set }}\left(\beta^{*}=0.2,-\mathrm{W}\right)$, i.e. no correction required. 
Table IV

IFEL Beam Transport Elements, Location and Parameters* (p. $=50 \mathrm{MeV} / \mathrm{c}$ )

\begin{tabular}{|c|c|c|c|c|c|c|c|c|}
\hline Element & $\begin{array}{l}\text { Magnet types \& } \\
\text { drift spaces }\end{array}$ & $\begin{array}{l}\text { Length } \\
\text { (m) }\end{array}$ & $\begin{array}{l}\text { Strength } \\
\left(\mathrm{m}^{-2}\right)\end{array}$ & $\begin{array}{l}\text { Gradient } \\
(\mathrm{kG} / \mathrm{m})\end{array}$ & $\begin{array}{l}\text { Field } \\
(\mathrm{kG})\end{array}$ & $\left\{\begin{array}{l}\text { Gdl(kG) } \\
\text { Bdl(kGm) }\end{array}\right.$ & $\begin{array}{l}\text { "Matching } \\
\text { Variables" }\end{array}$ & $\begin{array}{l}\text { "BETA" } \\
\text { Design. }\end{array}$ \\
\hline & SD & 0.55 & & & & & & \\
\hline \multirow[t]{2}{*}{$\mathrm{PQ7}$} & SLAC(IX) $30 \mathrm{~mm}$ & 0.1 & 0.0 & 0.0 & & 0.0 & - & (16) \\
\hline & SD & 0.25 & & & & & & \\
\hline \multirow[t]{2}{*}{$\mathrm{PO} 8$} & SLAC(IX) $30 \mathrm{~mm}$ & 0.1 & 12.5183 & 20.8781 & & 2.0878 & - & (13) \\
\hline & SD & 0.25 & & & & & & \\
\hline \multirow[t]{2}{*}{$\mathrm{PQ9}$} & $\mathrm{BEPC}(\mathrm{IX}) 40 \mathrm{~mm}$ & 0.1 & -10.0951 & -16.8367 & & -1.6837 & - & (1) \\
\hline & SD & 0.55 & & & & & & \\
\hline \multirow[t]{2}{*}{ TD1 } & Danfysik $20^{\circ}$ & 0.4 & & & 1.4554 & 0.5822 & & $(8.7 .8)$ \\
\hline & SD & 1.05 & & & & & & \\
\hline \multirow[t]{2}{*}{ TQ1 } & BEPC(IX) $40 \mathrm{~mm}$ & 0.1 & 6.6847 & 11.1488 & & 1.1149 & - & (2) \\
\hline & $\mathrm{SD}$ & 2.0 & & & & & & \\
\hline \multirow[t]{2}{*}{$\mathrm{TQ2}$} & $\mathrm{BEPC}(\mathrm{IX}) 40 \mathrm{~mm}$ & 0.1 & 5.7124 & 9.5272 & & 0.9527 & $=$ & (3) \\
\hline & SD & 2.0 & & & & & & \\
\hline \multirow[t]{4}{*}{ TQ3 } & BEPC(IX) $40 \mathrm{~mm}$ & 0.1 & -5.8174 & -9.7023 & & -0.9702 & - & (4.4) \\
\hline & SD & 1.05 & & & & & & \\
\hline & [DI] & 0.4 & & & 0.0 & & & (12) \\
\hline & SD & 0.55 & & & & & & \\
\hline \multirow[t]{2}{*}{ TQ4 } & BEPC(IX) $40 \mathrm{~mm}$ & 0.1 & 5.7124 & 9.5272 & & 0.9527 & - & (3) \\
\hline & SD & 2.0 & & & & & & \\
\hline \multirow[t]{4}{*}{ TQS } & $\mathrm{BEPC}(\mathrm{IX}) 40 \mathrm{~mm}$ & 0.1 & 6.6847 & 11.1488 & & 1.1149 & - & (2) \\
\hline & SD & 1.05 & & & & & & \\
\hline & Danfysik $20^{\circ}$ & 0.4 & & & -1.4554 & -0.5822 & & $(5.6 .5)$ \\
\hline & SD & 0.55 & & & & & & \\
\hline \multirow[t]{2}{*}{ TQ } & BEPC(IX) $40 \mathrm{~mm}$ & 0.1 & -5.9913 & -9.9923 & & -0.9992 & $*$ & $(31)$ \\
\hline & SD & 0.3 & & & & & & \\
\hline \multirow[t]{2}{*}{ TQ } & & 0.1 & $10-6651$ & 5.3325 & & 0.5333 & $*$ & (30) \\
\hline & SD & 1.35 & & & & & & \\
\hline \multirow[t]{2}{*}{ TQ } & & 0.1 & -11.2074 & -18.6918 & & -1.8692 & $*$ & (18) \\
\hline & SD & 0.45 & & & & & & \\
\hline
\end{tabular}


Table IV (cont'd)

IFEL Beam Transport Elements, Location and Parameters* (p. $=50 \mathrm{MeV} / \mathrm{c}$ )

\begin{tabular}{|c|c|c|c|c|c|c|c|c|}
\hline Element & $\begin{array}{l}\text { Magnet Types } \\
\text { \& Drift Spaces } \\
\end{array}$ & $\begin{array}{l}\text { Length } \\
\text { (m) }\end{array}$ & $\begin{array}{l}\text { Strength } \\
\text { (m) }\end{array}$ & $\begin{array}{l}\text { Gradient } \\
(\mathrm{kG} / \mathrm{m})\end{array}$ & Field $(\mathrm{kG})$ & $\begin{array}{l}\text { fdll(kG) } \\
\text { Bdl(kGm) }\end{array}$ & $\begin{array}{l}\text { "Matching } \\
\text { variables }\end{array}$ & $\begin{array}{l}\text { "BETA" } \\
\text { design. }\end{array}$ \\
\hline \multirow[t]{6}{*}{ TQ } & & 0.1 & 11.6924 & 19.5007 & & 1.9501 & $*$ & (20) \\
\hline & SD & 0.75 & & & & & & \\
\hline & & 0.4 & & & & & & \\
\hline & SD & 0.35 & & & & & & \\
\hline & $\mathrm{w}$ & 0.6 & & & & & & $(23.23)$ \\
\hline & SD & 0.35 & & & & & & \\
\hline \multirow[t]{2}{*}{ FD3 } & Danfysik $20^{\circ}$ & 0.4 & & & -1.4554 & -0.5822 & & $(5.6 .5)$ \\
\hline & SD & 0.9 & & & & & & \\
\hline \multirow[t]{3}{*}{ TQ } & $\begin{array}{l}\mathrm{BEPC}(2 \mathrm{X}) \\
40 \mathrm{~mm}\end{array}$ & 0.2 & 12.0000 & 20.0137 & & 4.0027 & & (25) \\
\hline & SD & 0.25 & & & & & & \\
\hline & SD & 0.1 & & & & & & \\
\hline TQ & & 0.2 & -10.0000 & -16.6781 & & -3.3356 & & (27) \\
\hline & SD & 2.0 & & & & & & \\
\hline & SD & 1.15 & & & & & & \\
\hline
\end{tabular}

Optical Parameters: at Collimator II $(5=0): \beta_{x}=\beta_{y}=10(m) ; \alpha_{x}=\alpha_{y}=\eta=\eta^{\prime}=0.0$ at IFEL interaction "point": $\beta_{\mathrm{x}}{ }^{*}=\beta_{\mathrm{y}}{ }^{*}=0.3(\mathrm{~m}), \alpha_{\mathrm{x}}{ }^{*}=\alpha_{\mathrm{y}}{ }^{*}=\eta^{*}=\eta^{*}=0.0$ 


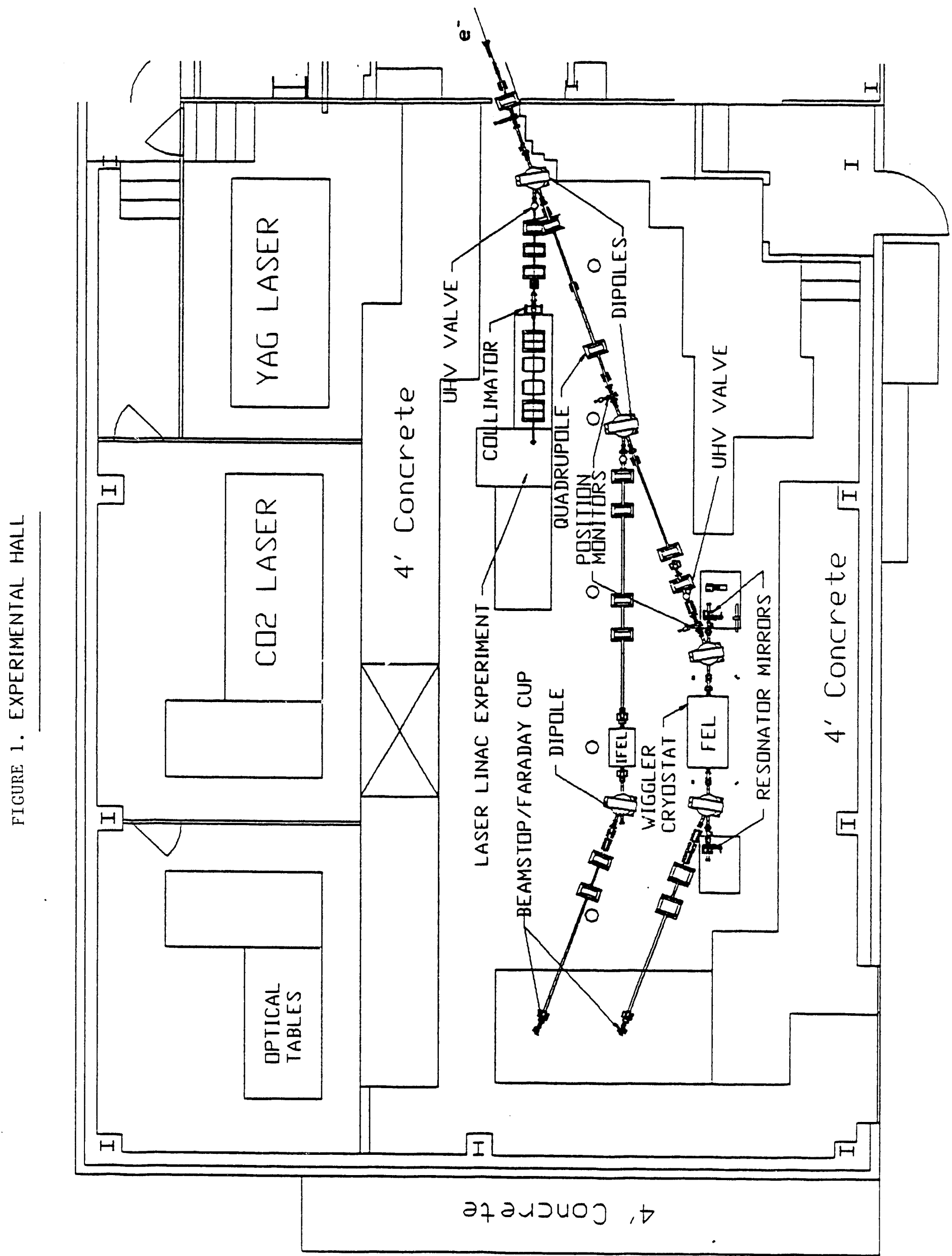


Fig.2, Wiggler Geometry (Schematic)

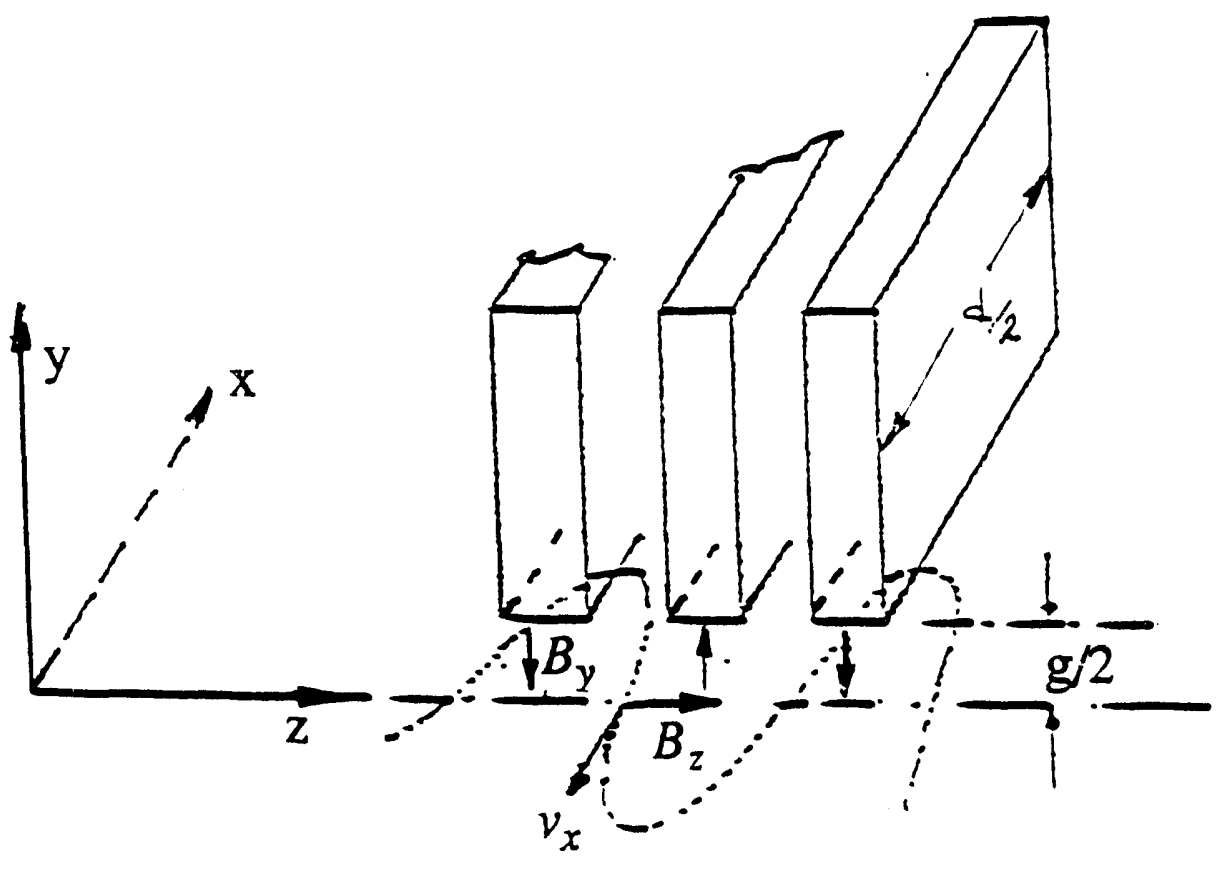




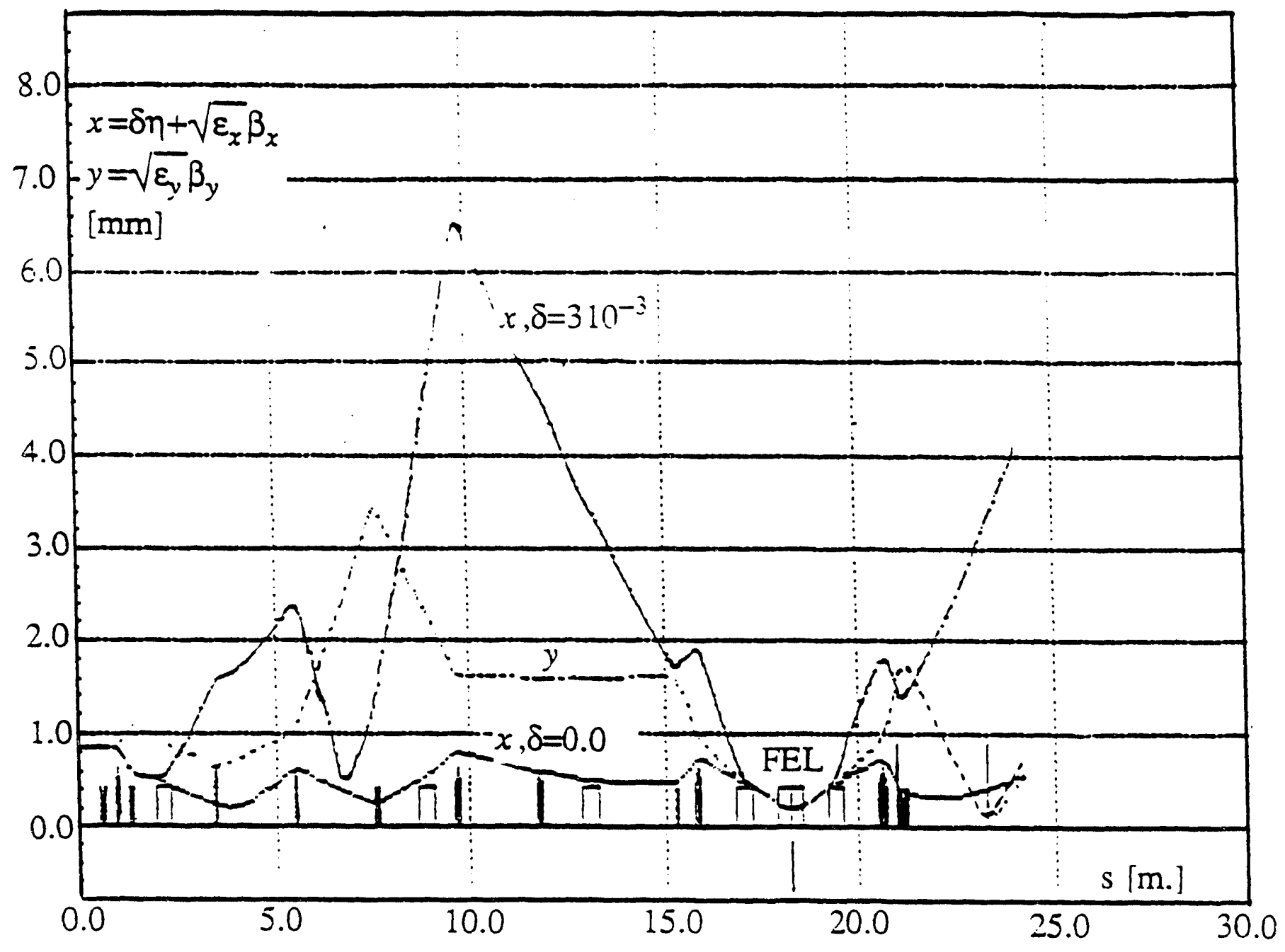

FIG. 3

Standard Optics for FEL operation

$$
\begin{aligned}
& \left(\sigma_{x}=\delta \eta+\sqrt{\varepsilon_{x}} \beta_{x}\right. \\
& \left(\beta_{x}^{*}=\beta_{y}^{*}=0.5 \mathrm{~m} \quad \alpha_{x}^{*}=\alpha_{y}^{*}=\eta^{*}=\eta^{*^{\prime}} \quad=0.0 \quad: \delta=0.0 \text { or } 3.010^{-3}\right) \\
& \left(\beta_{x}(0)=\beta_{y}(0)=10.0 \mathrm{~m} ., \quad \alpha_{x}=\alpha_{y}=\eta=\eta^{\prime}=0.0 \text { at } s=0.0\right) \\
& \left(R_{56}=0.01435 \Delta t= \pm 0.14 \mathrm{psec} \text { for } \delta= \pm 310^{-3} \text {, for }(s=0)-(s=*)\right)
\end{aligned}
$$




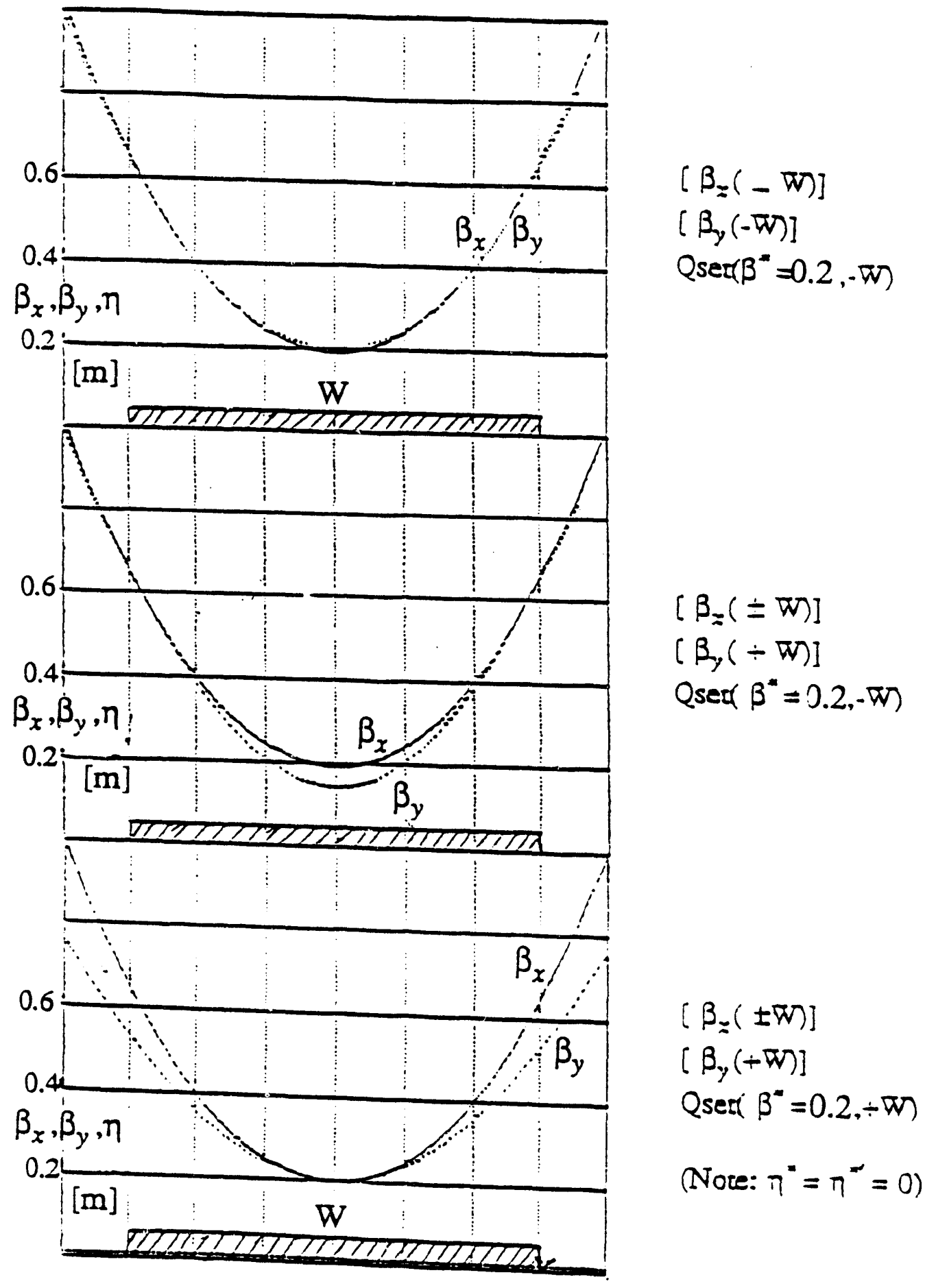

Fig.4

FEI Optics, \pm Wiggler** Insertion Effect $\beta^{*}=0.2 \mathrm{~m}$.

**(Wiggler parameters: $\rho_{0}=0.354 \mathrm{~m}, \lambda_{0}=0.0088 \mathrm{~m} . L_{\nu}=0.6 \mathrm{~m}$.)

$$
\left(\beta_{w}(n a x)=0.5 m \text {. }\right)
$$




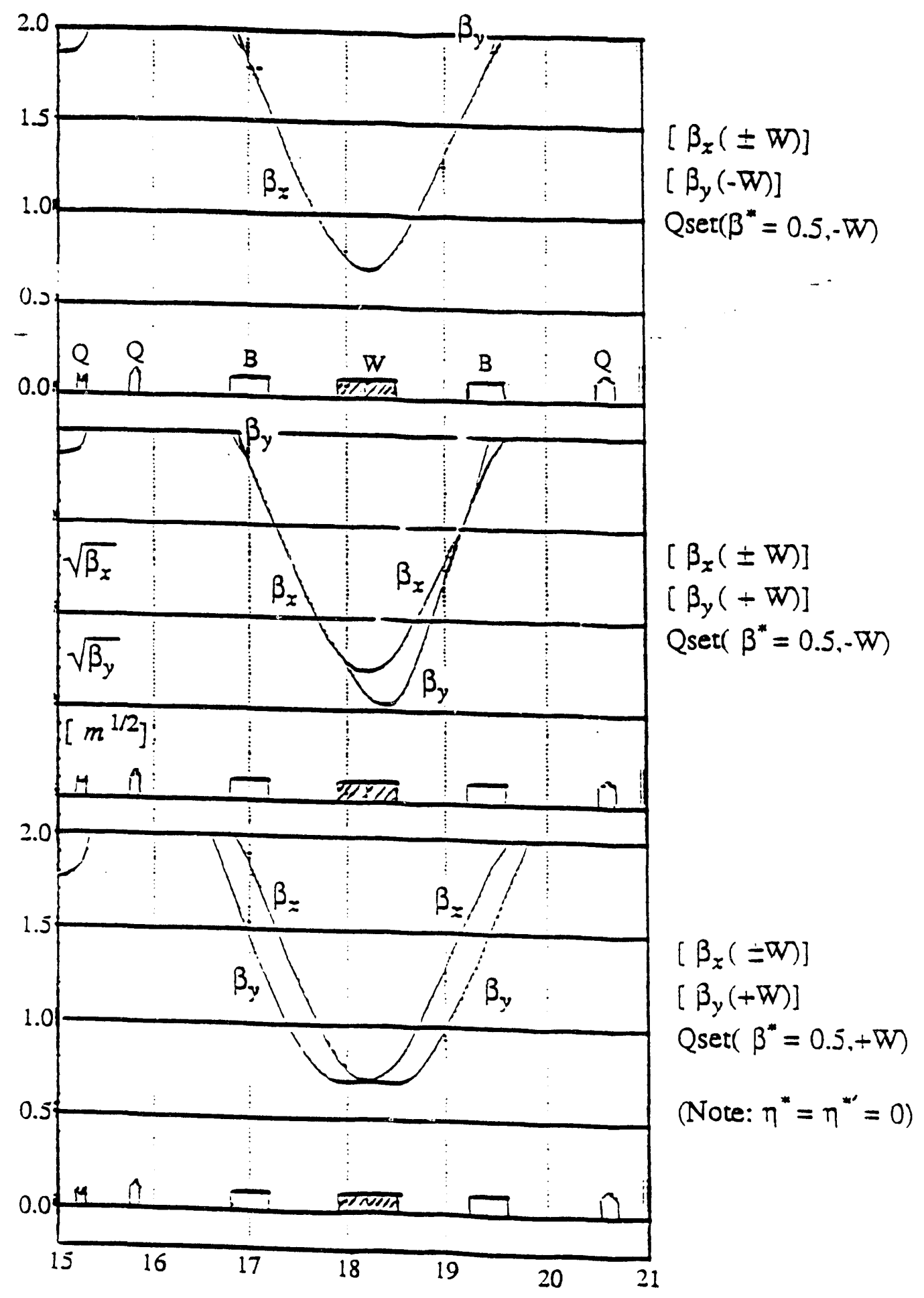

Fig.5

FEL Optics, \pm Wiggler** Insertion Effect, $\beta^{*}=0.5 \mathrm{~m}$. **(Wiggler parameters: $\rho_{0}=0.354 \mathrm{~m} ., \lambda_{0}=0.0088 \mathrm{~m} . L_{w}=0.6 \mathrm{~m}$.) $\left(\beta_{w}(n a t)=0.5 \mathrm{~m}.\right)$ 


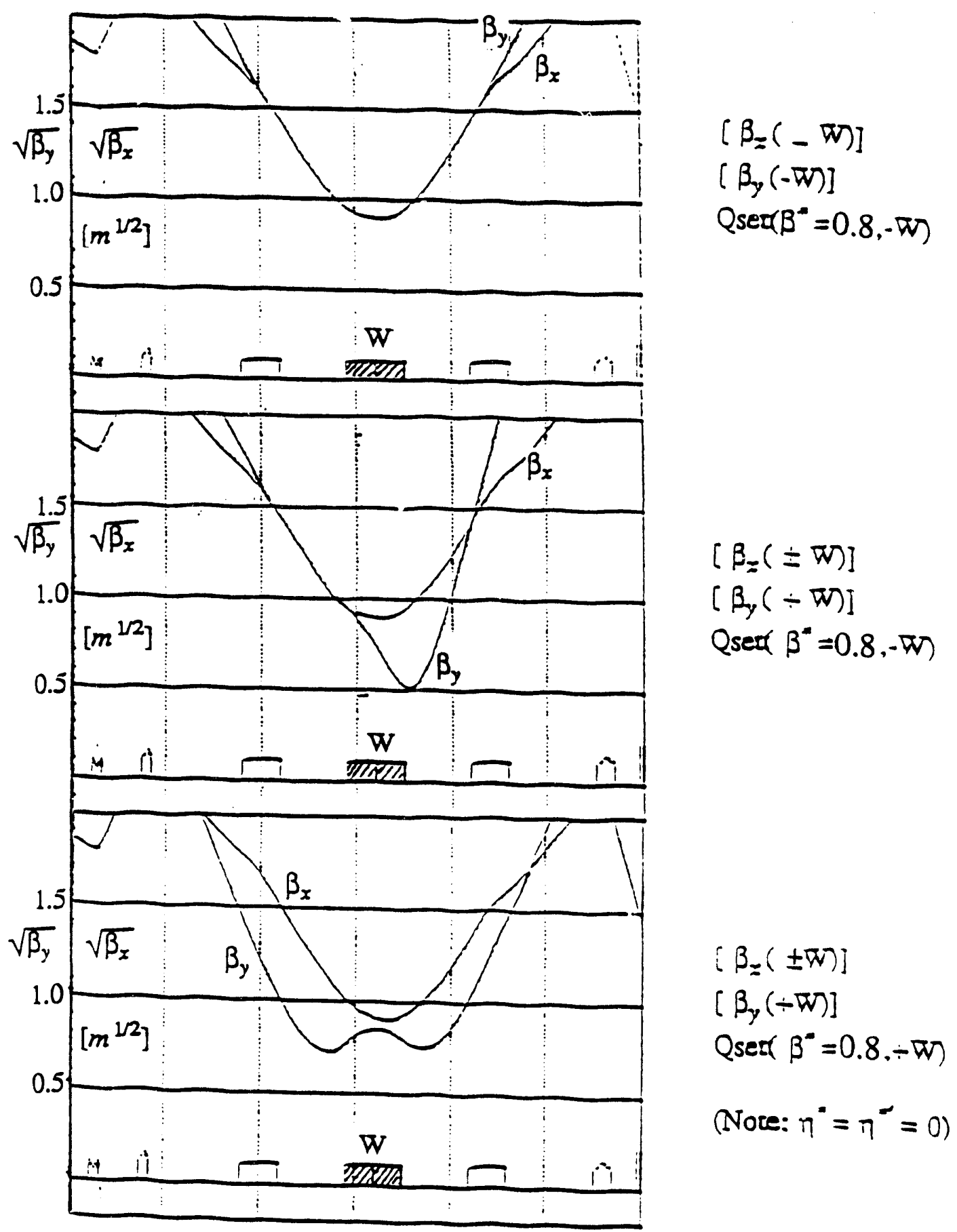

Fig.6

FEI Optics, \pm Wiggler** Insertion Effect $\beta^{*}=0.8 \mathrm{~m}$. **(Wiggler parameres: $\rho_{o}=0.354 \mathrm{~m} . \lambda_{0}=0.0088 \mathrm{~m} . L_{\nu}=0.6 \mathrm{~m}$.)

$$
\left(\beta_{w}(n a x)=0.5 \mathrm{~m}\right. \text {.) }
$$




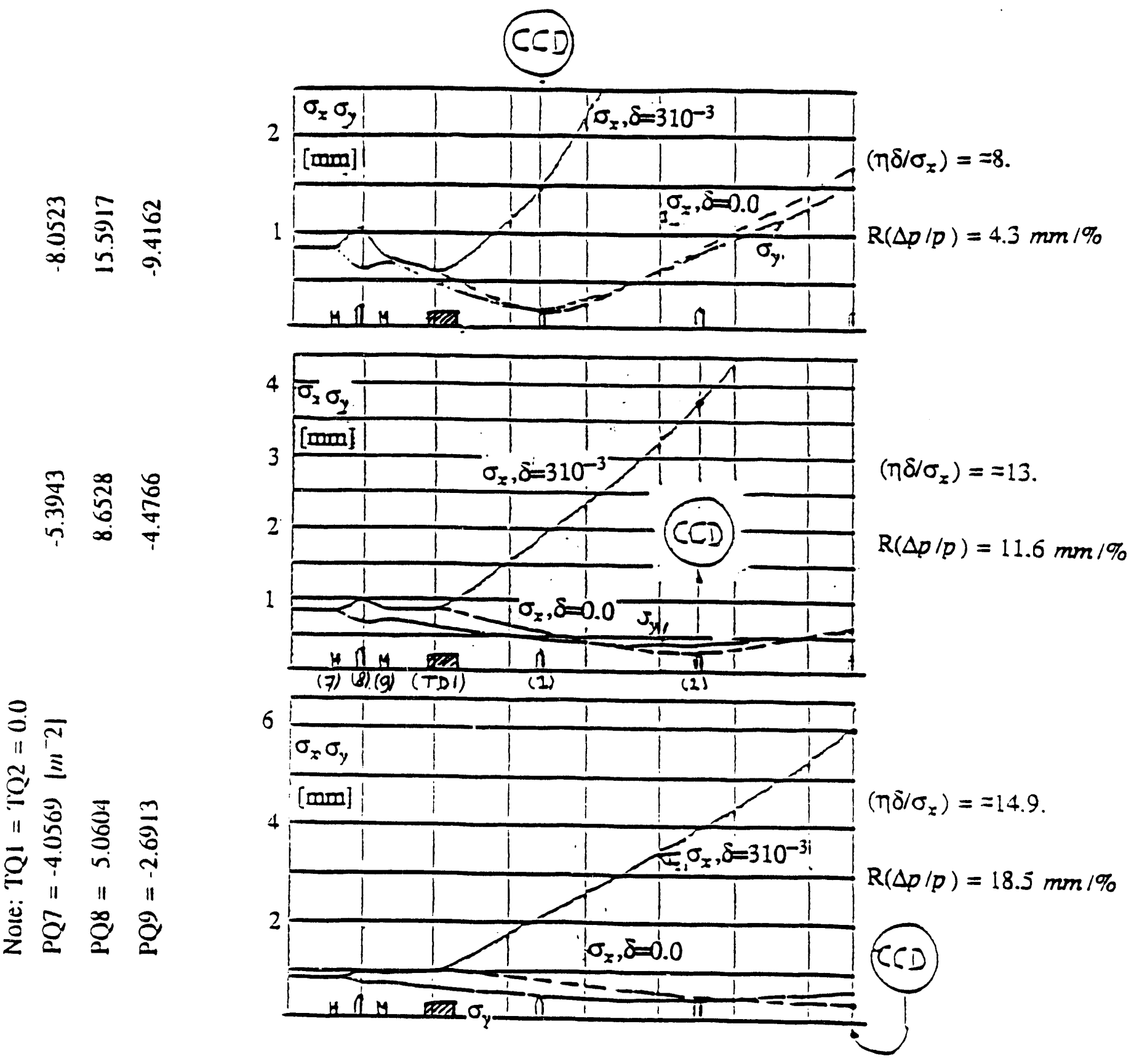

Special Optics for Enhanced Momentum Resolution ("front end")

$$
\left(\sigma_{x}=\sigma_{y}=7.10^{-8} \text { m.rad } ; \sigma_{x}=\delta \eta+\sqrt{\beta_{x}} \varepsilon_{x} ; \sigma_{y}=\sqrt{\beta_{y}} \varepsilon_{y}\right)
$$

Fig.7 


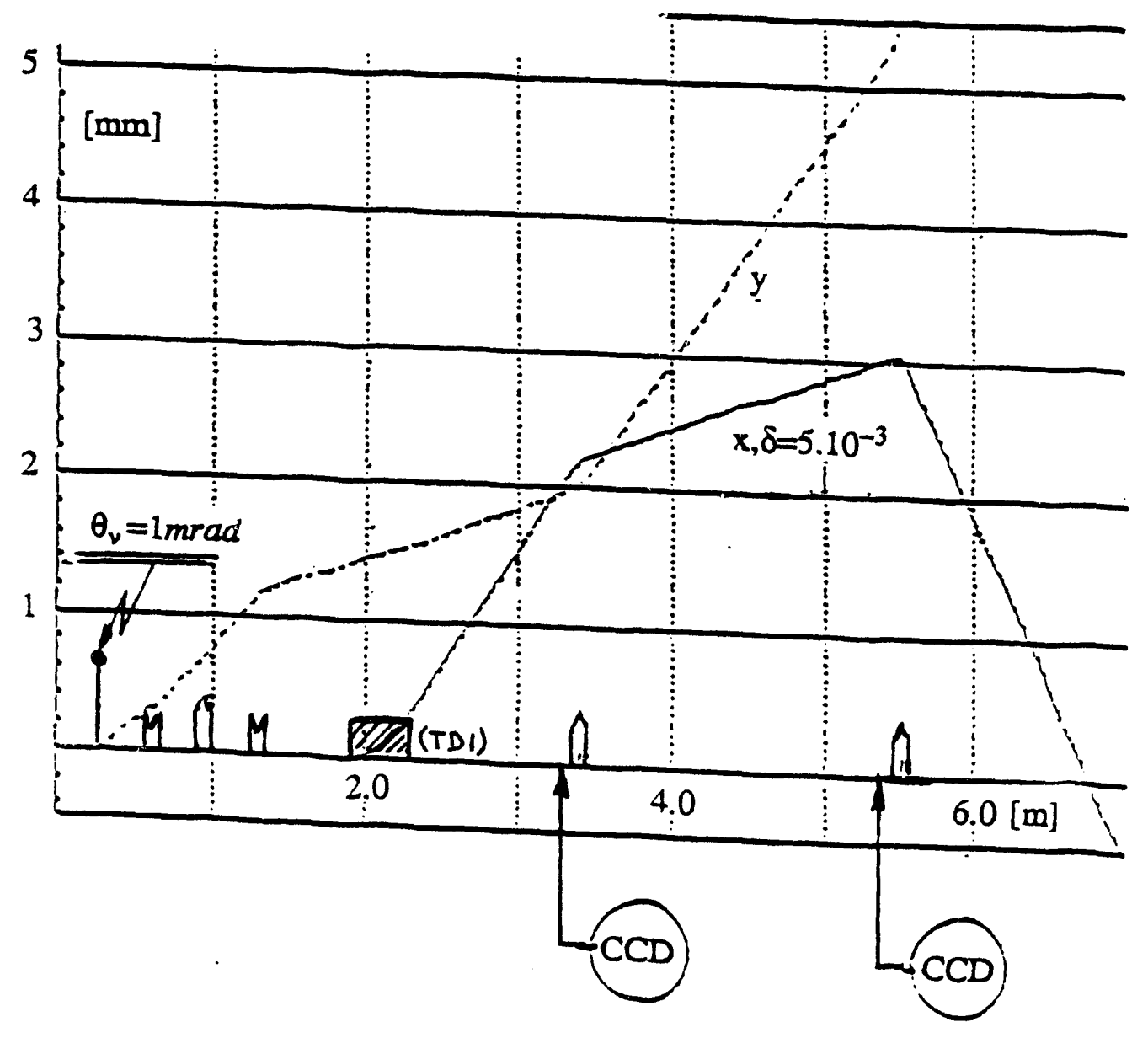

Diagnostics; Dispersion and Effect of a Vertical Kick in the

"Front End" Section with "Standard" FEL Optics

Fig.8 

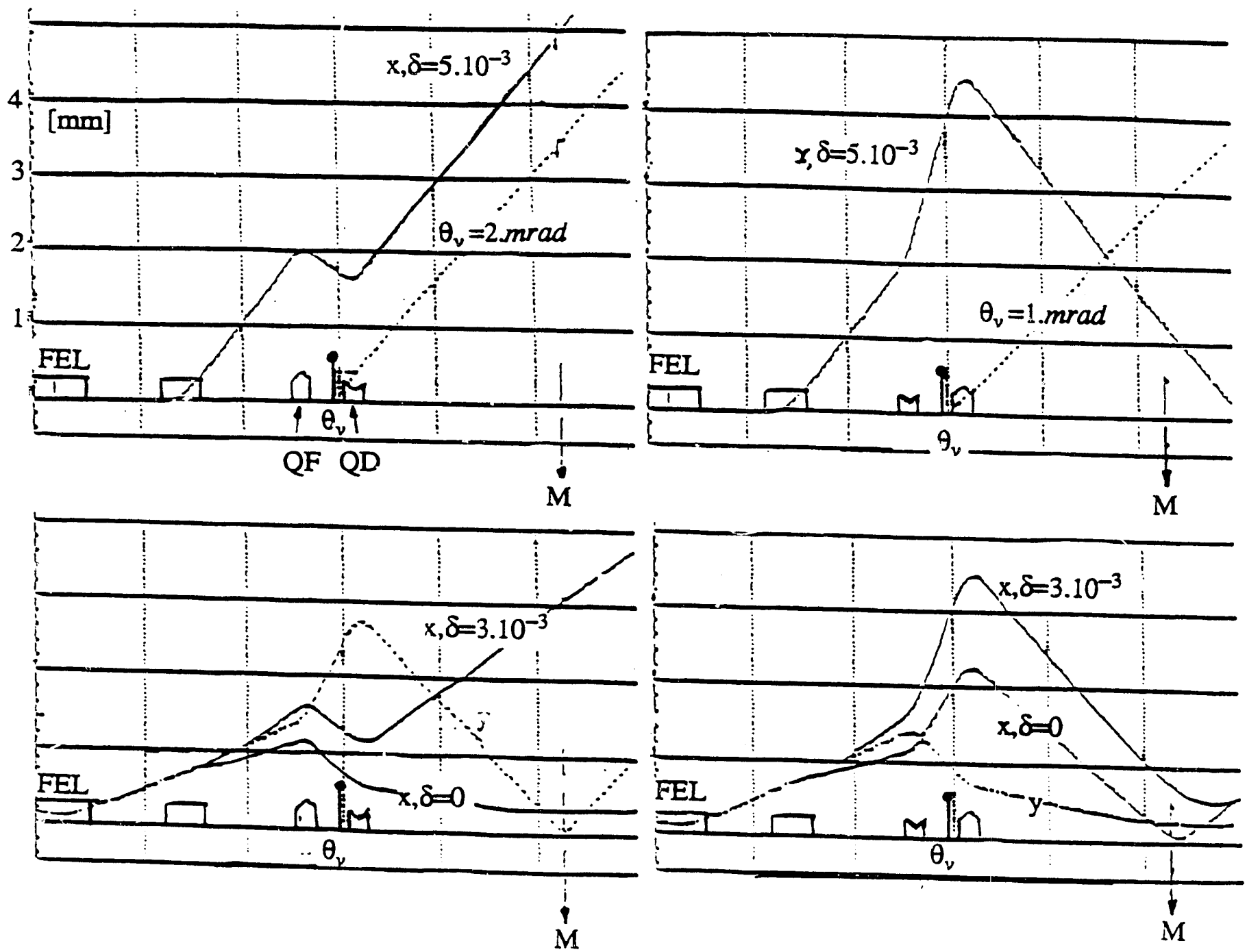

Diagnostics Downstream of the FEL Interaction Region

Fig.9

High Momentum Resolution Mode at M: $9.8 \mathrm{~mm} / 1 \% \Delta p / p$

Vert. $1.7 \mathrm{~mm} / 1 \mathrm{mrad} \theta_{v}$ (QF, QD set for "waist" at $M$ )
Reduced Momentum Resolution Mode at M: $2.5 \mathrm{~mm} / 1 \% \Delta p / p$

Vert. $3.0 \mathrm{~mm} / 1 \mathrm{mrad} \theta_{v}$ $\left(\mathrm{QF}=7.0 \mathrm{~m}^{-2}, \mathrm{QD}=-7.0 \mathrm{~m}^{-2}\right.$ 


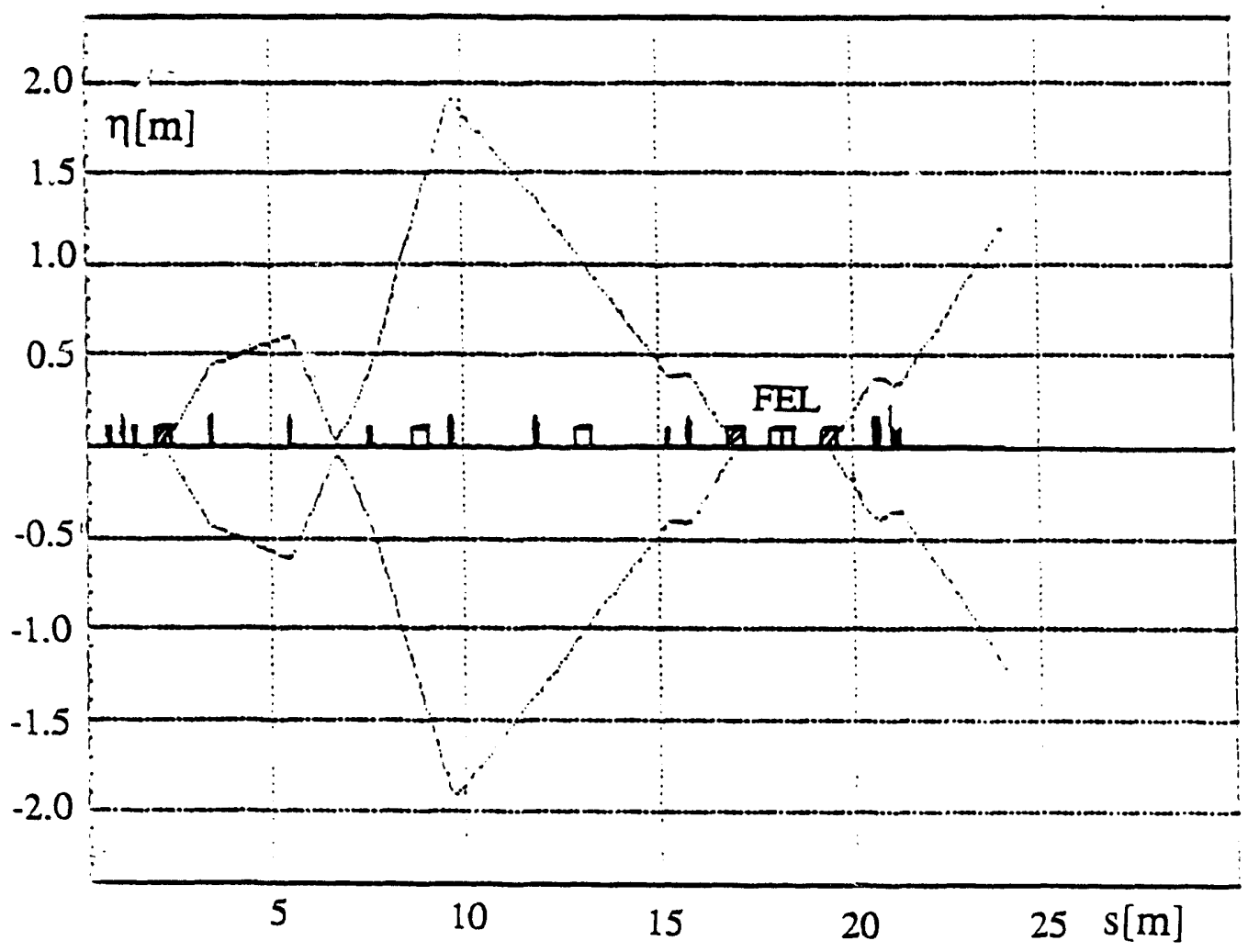

Guidance for Diagnostics

Momentum Dispersion with "Standard" FEL Optics $\left(\beta^{*}=0.5 \mathrm{~m}\right.$.)

Fig. 10 


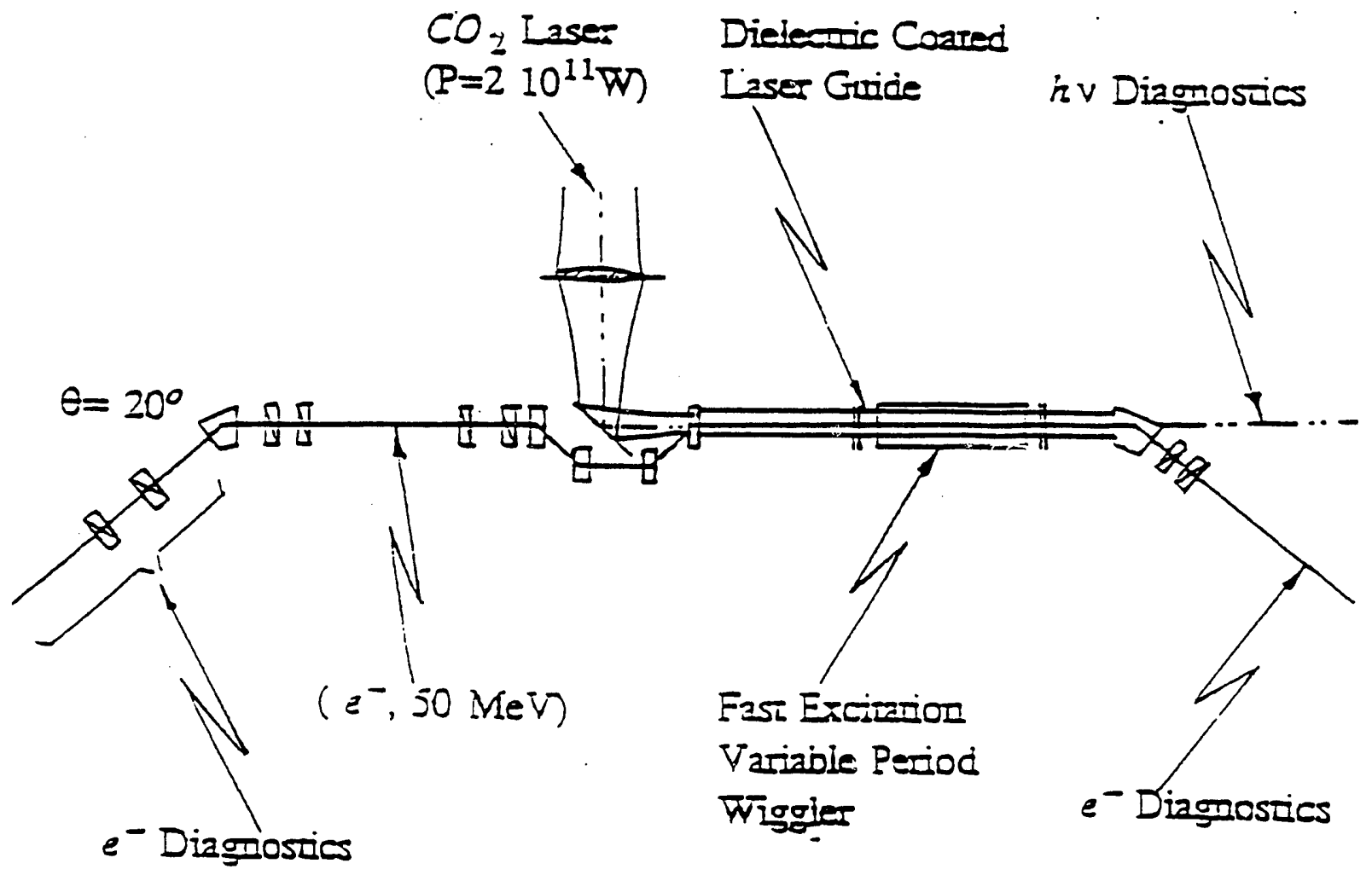

IFEL Accelerator Experiment (Schematic)

Fig.11 


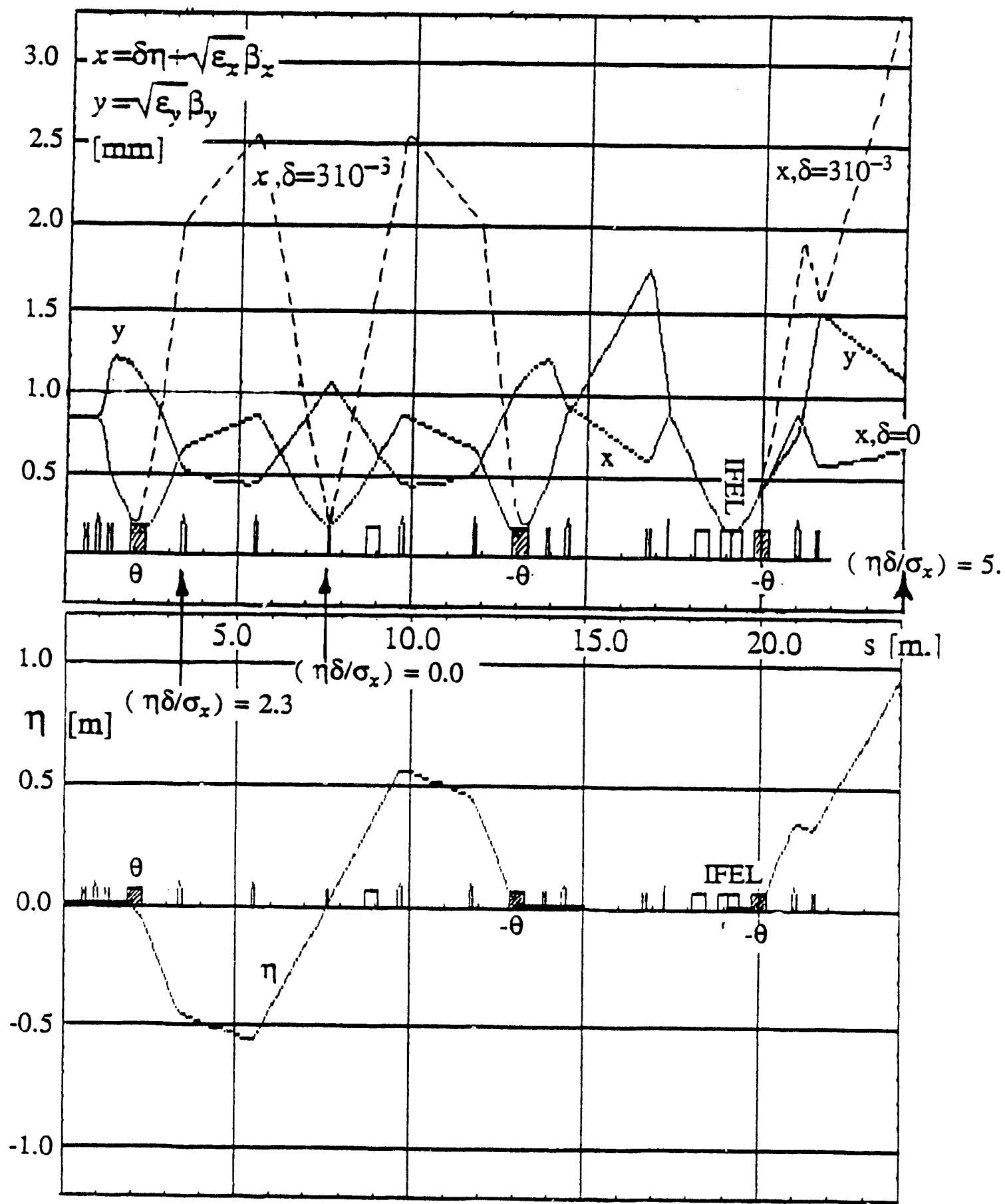

Fig. 12

Electron Beam Optics for the IFEL Experiment

$\left(\sigma_{x}=\delta \eta+\sqrt{\varepsilon_{x}} \beta_{x}\right.$

$\left(\beta_{x}^{*}=\beta_{y}^{*}=0.3 \mathrm{~m} . \quad \alpha_{x}^{*}=\alpha^{*}=\eta^{*}=\eta^{*} \quad \varepsilon_{x}=\varepsilon_{y}=710^{-8} \mathrm{~m} \cdot \mathrm{rad}\right)$

$\left(\beta_{x}(0)=\beta_{y}(0)=10.0 \mathrm{~m} ., \quad \alpha_{x}=\alpha_{y}=\eta=\eta^{\prime}=0.0 \quad\right.$ at $\left.s=0.0\right)$ 

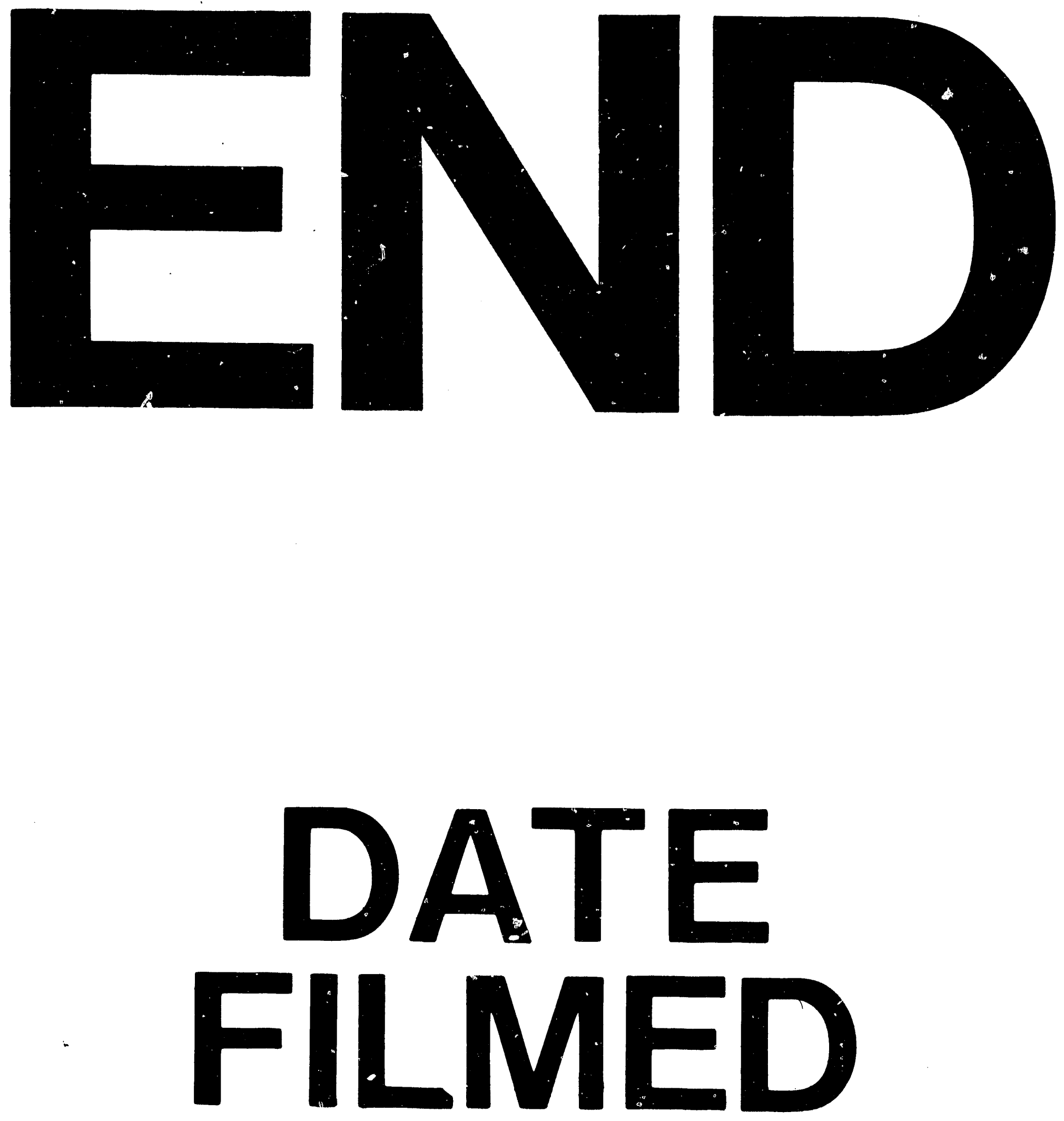

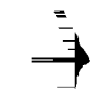

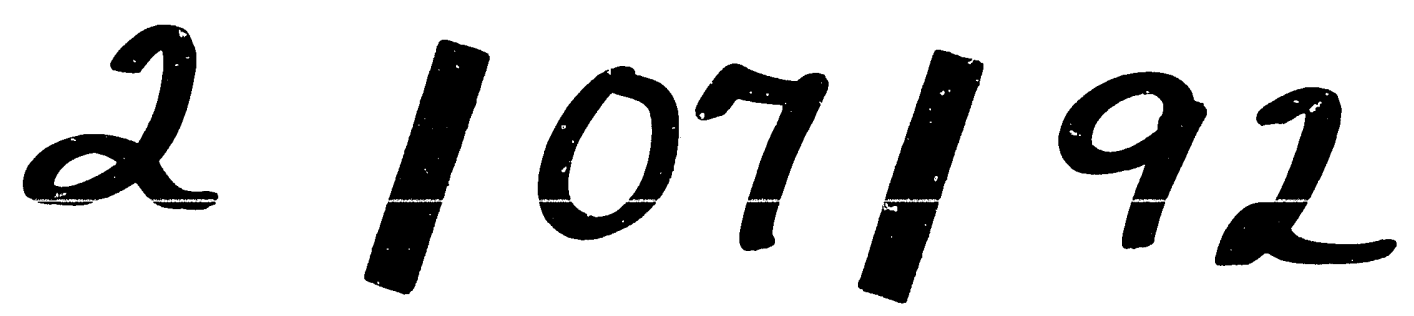


